\title{
Anatomia de uma injustiça secular \\ O Estado Novo e a regulação do serviço doméstico no Brasil
}

\section{Anatomy of a Century Long Injustice \\ The Estado Novo and Domestic Labor in Brazil}

\author{
Teresa Cristina de Novaes MARQUES ${ }^{1}$ \\ https://orcid.org/0000-0002-8452-6725 \\ ${ }^{1}$ Departamento de História \\ Universidade de Brasília \\ ICC Norte, Mezanino, Brasilia, DF, 70.910-900, Brasil \\ tcnovaes610@gmail.com
}

Resumo O artigo busca recuperar o processo político que levou à decisão de excluir os trabalhadores domésticos do alcance de proteção da Consolidação das Leis do Trabalho (CLT), editada em 1943. O debate em torno da situação jurídica dessa vasta categoria, onde predominavam mulheres pobres e negras, teve início na Constituinte de 1933-34 e se arrastou por uma década, contando com a interferência de diversos atores políticos. Para as ativistas feministas ligadas à Federação Brasileira pelo Progresso Feminino, o resultado da polêmica em torno da proteção do trabalho doméstico foi uma das muitas derrotas colhidas no Estado Novo, muito embora a defesa desta categoria não tivesse sido uma prioridade entre essas ativistas. A resultante do confronto de opiniões sobre o assunto guiou as políticas públicas para a categoria nas décadas seguintes à queda de Vargas.

Palavras-Chave emprego doméstico, legislação social, catolicismo de Estado

Recebido: 03 jun.2019 | Revisto pela autora: 11 ago. 2019 | Aprovado: 07 set. 2019 http://dx.doi.org/10.1590/0104-87752020000100007

Varia Historia, Belo Horizonte, vol. 36, n. 70, p. 183-216, jan/abr 2020 
Abstract This article seeks to reassess the political process that led to the exclusion of domestic workers from the 1943 Brazilian labor legislation known as the CLT. The public debate about the juridical condition of this vast labor category, in which poor and black women predominated, began in the 1933-1934 Constituent Assembly and dragged on for the following decade. Several political actors interfered in this debate. For the feminist activists linked to the Brazilian Federation for Women's Progress, the outcome of the controversy represented one of many defeats it suffered during the so-called Estado Novo, although the defense of domestic workers had never been a priority among its members. The outcome of the clash of opinions about this subject guided public policies for this group of workers in the decades following Vargas' fall from power in 1945.

KEYwords Domestic labor; social legislation; State Catholicism.

\section{Apresentação}

A sequência é conhecida: direitos civis, direitos políticos e direitos sociais foram sucessivamente estendidos às sociedades ocidentais desde o século XVIII até meados do século XX. O ensaio do sociólogo inglês T.H. Marshall sobre o processo histórico de construção da cidadania, mesmo publicado em 1950, ainda encontra acolhida nos estudos sobre o tema (Marshall, 1950).

Anestesiados pela perspectiva reconfortante de que os direitos viriam em sequência, conduzindo a uma inevitável integração do mundo ocidental a um padrão normal de convivência social, como sugere o pensamento de Marshall, os estudiosos da cidadania, a exemplo de Carvalho (Carvalho, 2003), perdem de vista que o processo histórico não se deu de forma linear, nem quanto ao gênero, nem quanto à raça. O que dizer dos direitos civis de mulheres casadas que, no Brasil, só foram tornados equânimes aos dos homens nos anos 1960 (Marques; Melo, 2008)? $\mathrm{O}$ que dizer de categorias funcionais que foram excluídas dos direitos sociais de amplo alcance, a exemplo da categoria "serviço doméstico", 
onde um exército de mulheres pobres militava nas cidades de todo o país? Não se pode afirmar que usufruíssem plenamente de direitos civis, nem de direitos políticos, uma vez que a maior parte não preenchia o requisito da alfabetização, tampouco contavam com previdência, um direito social que lhes era negado.

Este artigo visa examinar o processo decisório que levou à exclusão da categoria das empregadas domésticas da Consolidação das Leis do Trabalho (CLT), na suposição de que a extensão dos direitos sociais não foi uma consequência inevitável da expansão das relações capitalistas, que não se deu de forma homogênea em todos os setores sociais. Também não foi um mero descuido dos formuladores da legislação social varguista. No Brasil, houve setores, a exemplo da categoria serviço doméstico, em que as relações contratuais pactuadas no âmbito do público a muito custo substituíram as relações baseadas na pessoalidade.

Uma breve rememoração das iniciativas políticas recentes em favor da categoria dos trabalhadores domésticos nos leva a tomar a Emenda Constitucional n. 72, aprovada em 2013, como uma ruptura na história do injusto tratamento legal que os poderes públicos ofereceram a essa numerosa categoria. Apenas com a Emenda de 2013, a categoria foi comtemplada com os mesmos benefícios previstos aos demais trabalhadores na Constituição de 1988. No entanto, foi preciso aguardar a regulamentação da Emenda, o que só aconteceu em junho de 2015, para que os trabalhadores domésticos pudessem contar com o FGTS, com horas extras, com indenização por dispensa sem justa causa e pudessem usufruir de benefícios previdenciários mais amplos do que usufruíam até então. Quem acompanhou a imprensa nos dias que se seguiram à sanção presidencial da lei que regulamentou os novos direitos da categoria, recorda-se das manifestações contrárias à medida, muitas delas envoltas em argumentação de fundo racista.

Uma das razões pelas quais o serviço doméstico não foi beneficiado por proteção legal no Brasil, nem em numerosos países, diz respeito à concepção de trabalho. O que é trabalho, afinal? Trata-se de questão que inquieta cientistas sociais. $\mathrm{O}$ que se faz cotidianamente em casa, na reprodução da família, é uma forma de trabalho? Isso gera valor, ou 
seja, riqueza? Hoje, pensamos que sim, mas até o passado recente, tais atividades não eram consideradas produtivas e, logo, não mereciam ser remuneradas.

Antes de avançar nas questões substantivas do tema do artigo, convém fazer algumas considerações de ordem conceitual, uma vez que existem na literatura sobre mulher e o mundo do trabalho três conceitos: trabalho doméstico, trabalho doméstico remunerado, serviço doméstico. O primeiro conceito é aplicado para determinar as tarefas desenvolvidas pela mulher no âmbito doméstico - desde lavar, cuidar dos filhos, preparar alimentos - que contribuem para o bem-estar dos moradores do lar, mas não são consideradas produtivas. Há tempos, o tema suscita reflexões e continua a provocar estudiosos desejosos de identificar um dos principais motores da reprodução das desigualdades de gênero na sociedade (Rodriguez; Cooper, 2005).

O segundo conceito pode ser empregado para denominar as atividades que as mulheres realizavam em casa, mas que se destinavam a produzir mercadorias. Isso compreende desde bordados, costuras, manufaturas de sapatos, beneficiamento de couro e outras tantas atividades que compõem a cadeia produtiva da indústria, ainda que sejam realizadas fora do espaço físico da fábrica. Como costuma acontecer, os dados censitários não mostram claramente o peso de tais atividades na economia, mas, no Brasil, os observadores contemporâneos foram capazes de reconhecer a importância dessas atividades para o sustento de famílias operárias (Cerqueira, 1934). ${ }^{1}$

O terceiro conceito diz respeito ao trabalho de manutenção do lar e de cuidado de crianças que alguém faz em benefício de uma família que não é a sua. É usualmente denominado serviço doméstico na documentação, mas também pode surgir como trabalho doméstico remunerado (Perez; Cutuly; Garazi, 2018). Aqui, encontramos o conceito que se aplica ao problema examinado neste exercício investigativo. São serviços que terceiros prestam a famílias e que compreendem desde o

1 Cerqueira, Eugenia G. O problema do trabalho feminino. São Paulo: Centro de Estudos e Ação Social, 1934. Fundo: Ação Católica Brasileira, cx. 8. 
cuidado de crianças, limpeza da residência, preparo de alimentos, até a condução do automóvel da família. Exceto por esta última atividade, majoritariamente realizada por homens, as demais eram feminilizadas.

A opinião corrente entre os homens influentes no governo Vargas, o que eu chamarei no âmbito deste artigo de concepção histórica de valor-trabalho, insistia em não considerar o trabalho cotidiano realizado nos banheiros, nas cozinhas e no chão das casas de família como algo que agregasse valor à riqueza social. Em verdade, a visão predominante do assunto mal disfarçava a persistência de relações patriarcais que regiam a dinâmica de poder na família, onde serviçais se situavam de forma subordinada.

O artigo examina um período histórico pouco explorado nos estudos sobre a categoria das empregadas domésticas, que se dedicam, habitualmente, às últimas décadas do século XIX e à primeira década após a emancipação da escravidão. A pesquisa apresentada neste ensaio enfatiza a forma como a questão foi tratada durante o primeiro governo Vargas, a partir de um conjunto amplo de fontes, que compreendem desde debates parlamentares, a matérias patrocinadas pelo governo em jornais e em publicações oficiais. A pesquisa também revelou que a elaboração da legislação complementar à Constituição de 1934, que estava em curso na Câmara dos Deputados, não foi suspensa com o fechamento do Legislativo, em novembro de 1937. O debate político se deslocou então para o Ministério do Trabalho, que continuou a enviar documentos para a Câmara. Embora não houvesse mais deputados reunidos para deliberar sobre as matérias, o sistema de arquivamento de documentos relativos a matérias de legislação social continuou a acontecer. Essa é a nossa hipótese explicativa para o fato de o Arquivo da Câmara preservar documentos sobre o debate em torno da regulação do trabalho doméstico, datados de anos posteriores ao fechamento do Legislativo.

Supõe-se que o resultado do debate público em torno da regulação do serviço doméstico durante o primeiro governo Vargas foi crucial para definir os parâmetros pelos quais o Estado passou a tratar da ampla categoria de mulheres que prestavam serviços às famílias nas décadas 
seguintes. A exclusão das empregadas domésticas da proteção legal de alcance nacional foi uma escolha política, para a qual muitos atores contribuíram. Dentre eles, estiveram os parlamentares da legislatura 1935-1937, além de setores da Igreja Católica. Também as feministas ligadas à Federação Brasileira pelo Progresso Feminino (FBPF) apresentaram propostas sobre a matéria e mantiveram interlocução política com membros do governo, mas acabaram por recuar da posição que defendiam no início da década de 1930.

A insatisfatória compreensão que ainda temos sobre o assunto resulta do pouco domínio da história parlamentar do período, bem como das tramas políticas internas ao governo Vargas no que diz respeito à questão do serviço doméstico. Este artigo busca contribuir para elucidar questões neste debate.

\section{ESTADO E TRABALHO DOMÉSTICO}

O serviço doméstico é muito antigo no Brasil. Em toda parte, era disseminada a posse de mulheres escravizadas que cuidavam da casa e dos filhos dos senhores. Concomitante à escravidão vivida no ambiente doméstico, ao longo do século XIX, surgiu um mercado de trabalho em expansão para mulheres pobres e livres. Muitas dessas trabalhadoras eram imigrantes originárias de Portugal, onde os níveis de pobreza expulsaram a população de aldeias do Minho. Nos anos que se seguiram imediatamente à abolição do cativeiro, houve intensa movimentação política para gerar novas formas de controle sobre a população pobre que servia às famílias. Tais iniciativas políticas se concretizaram em posturas municipais.

A significativa historiografia de que dispomos sobre o assunto se debruça sobre as décadas do pós-abolição a fim de compreender o pensamento político que guiou as câmaras municipais quando elaboraram posturas que delimitavam a atividade das empregadas domésticas (Souza, 2015; 2017; Silva, 2011). O resultado desse esforço de investigação em arquivos municipais está revelando um cotidiano de exploração, violência e de racismo a que as mulheres pobres estavam sujeitas (Freitas, 2009; Cunha, 2007). 
Nas décadas seguintes, a esfera local continuou a chamar para si a competência para baixar regulamentos, que incluíam dispositivos de controle policial, responsáveis por regular o ofício das empregadas domésticas. Sobre as trabalhadoras, recaiam os estigmas de desonestidade, despreparo e lascívia. Assim, essas mulheres conviviam com violências físicas e emocionais cotidianamente ao procurar o sustento de suas famílias. O já clássico estudo de Roberto Moura (Moura, 1995) mostrou que, na memória da comunidade surgida em torno da líder religiosa, Tia Ciata, enquanto os homens entravam e saíam do mercado de trabalho do Rio de Janeiro, enfrentando a oferta sazonal de trabalho, as mulheres tinham duas alternativas para assegurar o sustento dos núcleos familiares: ou se empregavam em casas de família, ou vendiam alimentos em quitandas.

A chegada de Vargas ao poder em 1930 mudou o cenário das relações de trabalho, que passaram a receber crescentes intervenções do Estado na forma de decretos-lei e de mediação de conflitos, o que se deu a partir da instalação de juntas de conciliação no Ministério do Trabalho. Um controverso decreto-lei de 1932 buscou alinhar o país às diretrizes da Organização Internacional do Trabalho, no que concernia às ocupações laborais realizadas por mulheres. Entretanto, o decreto tratou apenas de mulheres empregadas na indústria e no comércio. ${ }^{2}$

As feministas ligadas à Federação Brasileira pelo Progresso Feminino (FBPF), estavam atentas às movimentações do governo para regular a presença de mulheres no mundo trabalho e dispostas a dar uma guinada na agenda política da própria entidade, até então centrada na demanda de igualdade política (Marques, 2016a). Criticaram o decreto de 1932 por aplicar mais interditos à presença de mulheres em ofícios do que o previsto nos documentos da Organização Internacional do Trabalho (OIT). Criticaram-no também por não estabelecer o compromisso de o empregador oferecer creches e, acima de tudo, por adotar

2 BRASIL. Ministério do Trabalho, Indústria e Comércio. Legislação trabalhista. Consolidação das Leis do Trabalho. 3a edição. Rio de Janeiro: A. Coelho Branco, 1949.Decreto-lei n. 21.417, 17 mai. 1932. 
o afastamento pós-parto sem oferecer a garantia da permanência no emprego (Marques, 2016b). Neste momento, a categoria das empregadas domésticas ainda estava invisível nas manifestações da FBPF.

Quantas eram essas trabalhadoras, afinal? Conforme o Censo de 1920, 58.895 mulheres que viviam no Distrito Federal, de todas as idades, atuavam no serviço doméstico. ${ }^{3}$ Isso significa que $10,5 \%$ das mulheres residentes na capital do país prestavam serviço nos lares, a exercer as mais variadas funções. A categoria não era composta exclusivamente por mulheres, mas nela predominava o sexo feminino.

Como é sabido, o Censo de 1940 não é perfeitamente comparável ao de 1920, em razão de divergências de metodologia, ainda assim, é possível ter uma ideia da situação da atividade no Distrito Federal 20 anos depois. Nesse tempo, a população total da cidade variou 1,15\% apenas, ao passo que a população feminina (entre 0 e 59 anos) empregada no setor de serviço doméstico remunerado cresceu sete vezes. Se, em 1920, havia 58.895 mulheres assim empregadas, em 1940, este contingente passou a ser de 496.100, ou 59,9\% das habitantes da Capital Federal. ${ }^{4}$

Outro aspecto importante é que o Censo de 1940 apresenta dados sobre cor da pele. Havia, então, 827.823 mulheres em idades entre 0 e 59 anos vivendo na cidade. Dessas, $30 \%$, ou 256.594 mulheres, foram identificadas como negras ou pardas. ${ }^{5}$ Ora, os dados do Censo não permitem estabelecer quantas mulheres negras e pardas ganhavam a vida como empregadas domésticas no Distrito Federal. No entanto, estudos qualitativos como os apresentados por Moura (Moura, 1995) indicam a

3 BRASIL. Ministério da Agricultura, Indústria e Comércio. Diretoria Geral de Estatística. Recenseamento do Brasil realizado em 1 set. 1920. Vol. II (1 ${ }^{\text {a }}$ Parte), Distrito Federal. Rio de Janeiro: Tipografia da Estatística, 1923. p.CXVIII, 26-27.

4 BRASIL. IBGE. Recenseamento Geral do Brasil, 1 set. 1940. Série Nacional, vol. II. População e Habitação. Rio de Janeiro: Serviço Gráfico do Instituto Brasileiro de Geografia e Estatística, 1950. p.140-141.

5 Os recenseadores foram instruídos a perguntar às pessoas se elas se consideravam brancas, pretas, amarelas ou pardas. Caso o entrevistado não desejasse escolher uma dessas classificações, era contabilizado como "cor não declarada". [Censo, 1940, Série Nacional, vol. II, p.xxi.] 
importância dessa forma de emprego para a população negra residente na cidade.

Com respeito à categoria, a única manifestação do Governo Provisório foi no sentido de proibir a sindicalização de empregadas domésticas e de servidores públicos. ${ }^{6}$ Apenas a segunda categoria conseguiu contornar a proibição e elegeu representantes à Assembleia Constituinte instalada em novembro de 1933. Como é sabido, a sindicalização da categoria das domésticas continuou a ser proibida por décadas.

Enquanto baixava normas relativas ao trabalho e à sindicalização da maior parte das categorias funcionais existentes no Brasil, o governo Vargas manteve-se em silêncio quanto à forma de tratar o serviço doméstico. Tal omissão não significa que o assunto não fosse debatido no âmbito da política institucional.

Em sua plataforma eleitoral para o pleito de maio de 1933, a candidata Bertha Lutz buscou se apresentar aos eleitores como defensora dos direitos de todos os trabalhadores, embora tivesse direcionado sua campanha para os funcionários públicos e os comerciários (Marques, 2016a). Seu discurso eleitoral reiterava o princípio do salário igual para o trabalho igual, que percorria o mundo desde fora enunciado pela Organização Internacional do Trabalho, em 1919. Lutz buscava sensibilizar as mulheres instruídas, suas potenciais eleitoras. A candidata declarou ao jornal A Noite: "A trabalho igual, salário igual sem distinção do sexo do trabalhador, fórmula que necessita ser aplicada a toda a atividade feminina, desde a advocacia, a engenharia, a medicina, até o emprego doméstico".

A menção à categoria das empregadas domésticas neste contexto cumpre o papel de chocar o público conservador e de construir uma persona pública audaz a ponto de defender a extensão da justiça social às camadas menos representadas na sociedade política. De fato, instalada

6 BRASIL. Ministério do Trabalho, Indústria e Comércio. Legislação trabalhista. Consolidação das Leis do Trabalho. 3a edição. Rio de Janeiro: A. Coelho Branco, 1949. Decreto n. 19.770, 19 mar. 1931, art. 11, § único, alínea b.

7 A Noite, 1 mai. 1933, p.2. 
a Constituinte, as feministas da FBPF atuaram nos bastidores para defender prioritariamente $\mathrm{o}$ acesso de mulheres às carreiras públicas, na aposta de que mulheres de classe média que ingressassem na administração pública viriam a recompor os quadros da entidade, sempre às voltas com a instabilidade no número de associadas.

Entretanto, na segunda quinzena de abril de 1934, chegado o momento de votar o capítulo da Ordem Social, uma inovação do texto em discussão, a redação do capítulo que chegara aos parlamentares pelas mãos do relator da matéria estendia o direito de afastamento pós-parto apenas à gestante operária. De pronto, um conjunto de deputados liderados pelo mineiro João Beraldo fez chegar à mesa uma emenda de redação, justificada da seguinte forma: "Desde que se proteja a gestante operária, por que não estender a toda mulher que trabalha a mesma proteção? A empregada doméstica, ou comercial e a trabalhadora rural são tão necessitadas quanto a trabalhadora industrial".

A emenda liderada por Beraldo e assinada por outros 64 parlamentares foi acatada pelo relator. Logo, a princípio, a Constituição de 1934 admitiu que os direitos sociais alcançavam as empregadas domésticas. A iniciativa de Beraldo em 1934 contou com o apoio de nomes de peso nas bancadas católica e tenentista, a exemplo do padre Arruda Câmara e de Amaral Peixoto. Contou igualmente com a assinatura dos mais combativos representantes classistas de empregados na Assembleia: Alberto Surek (têxteis/MG), Antônio Rodrigues (estivadores/DF), Gilbert Gabeira (eletricitários/ES), Guilherme Plaster (metalúrgicos/ $\mathrm{SP}$ ), Nogueira Penido (funcionários públicos/DF), entre outros. ${ }^{9}$

8 BRASIL. Câmara dos Deputados. Regimento Interno da Assembleia Nacional Constituinte. Rio de Janeiro: Imprensa Nacional, 1934. Emenda n. 720, abr. 1934. Consultei o exemplar autografado que é preservado no Arquivo da Câmara dos Deputados. O texto foi reproduzido no Diário da Assembleia Nacional (Suplemento), 6 mai. 1934, p.75.

9 Esclareço ao leitor que atribuo ao deputado Beraldo a autoria da emenda porque, pelo regimento dos trabalhos constituintes, o primeiro signatário de uma emenda era considerado o seu proponente. Entre outras prerrogativas, cabia ao autor e ao relator da matéria encaminhar a sua votação, fazendo o uso da palavra. 
Quem era, portanto, o deputado João Beraldo? Tratava-se de deputado eleito pela região de Pouso Alegre, cidade de que fora prefeito, sendo ligado ao líder político mineiro Olegário Maciel. Era deputado regular, isto é, elegeu-se pelo voto universal. Não foi escolhido por delegados sindicais, como o foram os deputados classistas. ${ }^{10}$ Saiu candidato pela legenda do Partido Progressista, uma agremiação criada para concorrer no pleito de maio de 1933. Chegou à Câmara com o significativo capital político de 190 mil votos em seu estado.

Advogado e jornalista, Beraldo não adquiriu formação política nos meios sindicais, a exemplo de deputados classistas eleitos para a mesma assembleia. No entanto, seu perfil informa que era próximo a Bertha Lutz, que teria assim se pronunciado a seu respeito: "O dr. João Beraldo, segundo as tradições mineiras tranquilamente conservadora e construtora, procurou seguir ao movimento feminista na mais cara das suas aspirações. Foi sua a iniciativa excluindo a mulher do serviço militar"."11

A publicação organizada por Godinho constitui uma espécie de quem-é-quem na Constituinte e o perfil de cada parlamentar é composto por texto fornecido pelo próprio deputado eleito para a Assembleia. Tomemos, portanto, a citação da fala de Lutz como uma sinalização deliberada de proximidade política entre o deputado mineiro e a líder feminista.

De fato, mesmo ausente dos trabalhos constituintes por não ter alcançado votos suficientes para ocupar uma cadeira de titular, Lutz fez chegar à assembleia as demandas da FBPF pelas mãos de aliados políticos ali presentes. Beraldo foi o mais importante defensor das teses feministas vitoriosas na Constituinte: igualdade de acesso a carreiras públicas, isenção do serviço militar para mulheres e a defesa de políticas

10 Dos 254 deputados constituintes, 17 foram eleitos por sindicatos de empregadores, 18 por sindicatos de empregados (de variadas categorias), 2 foram escolhidos por funcionários públicos e 3 foram eleitos por profissionais liberais. Sobre o assunto, ver: GODINHO, Wanor; ANDRADE, Oswaldo. Constituintes brasileiros de 1934. Rio de Janeiro: Ed. do Autor, 1934.

11 GODINHO, Wanor; ANDRADE, Oswaldo. Constituintes brasileiros de 1934. 
públicas em favor da maternidade, na forma de um conselho técnico destinado a essa matéria. ${ }^{12}$

No entanto, a matéria da proteção à maternidade não era cara exclusivamente às feministas ligadas à FBPF, uma vez que a bancada eleita pela Liga Eleitoral Católica para a constituinte aplicou grande energia política na sua aprovação. Em verdade, foram os católicos os maiores responsáveis por incluir o assunto na Constituição. Guiados pela doutrina das encíclicas papais que, desde a edição da encíclica Rerum Novarum, em 1891, inspiravam a reação católica às mudanças sociais trazidas pela modernidade, os líderes religiosos almejavam restaurar a ordem social em moldes cristãos. Para tanto, era necessário afastar as mulheres do mundo do trabalho, uma vez que se admitia o exercício de atividade remunerada apenas se o chefe da família não fosse capaz de sustentá-la sozinho, como argumentavam os pensadores católicos então, a exemplo de Cerqueira (Cerqueira, 1934).

Em complemento às ideias sobre as mudanças decorrentes da expansão das relações de trabalho no mundo industrial, uma encíclica editada em 1930, a Casti connubii, exortava os católicos a defender a sociedade doméstica das ameaças que rondavam a família, entre elas, a do divórcio e a da emancipação econômica da mulher. ${ }^{13}$ Resultou desse conjunto amplo de ideias que passaram a circular no meio social a condenação moral a que mulheres casadas se dedicassem a atividades remuneradas. Esse pensamento era tão disseminado que as repartições públicas estavam repletas de pedidos de exoneração de funcionárias sob a alegação de: "por motivo de núpcias". ${ }^{14}$

12 Emendas lideradas pelo deputado João Beraldo: n.718 (isenta mulheres do serviço militar), n. 719 (igualdade de exercício de funções públicas), n. 720 (estende proteção maternal a todas as trabalhadoras), n. 721 (igualdade nomeação para o Conselho Nacional), n. 722 (criação de 12 conselhos técnicos na esfera federal). [Arquivo da Câmara dos Deputados] BRASIL. Câmara dos Deputados. Regimento Interno da Assembleia Nacional Constituinte. Rio de Janeiro: Imprensa Nacional, 1934.

13 PIO XI. Sobre o matrimônio cristão. Rio de Janeiro: Vozes, 1956. [Col. Documentos Pontifícios, vol. 4]

14 Fundo Ministério do Trabalho, Indústria e Comércio - Arquivo Nacional, Brasília. Caixas: 29,55 . 
Para as trabalhadoras na indústria, o efeito prático da legislação baixada pelo Governo Provisório e reforçada pela Constituição foi tornar mais difícil o emprego formal de mulheres casadas, porque estava implicado no decreto de 1932 que o empregador arcaria com o custo do afastamento pós-parto das trabalhadoras. Assim, os empregadores passaram a preferir contratar apenas operárias solteiras.

Cientes do nó causado pela legislação de proteção à maternidade, ainda que tivessem convicção de que a condição da trabalhadora-mãe devesse receber atenção e proteção do Estado, as feministas da FBPF insistiam na necessidade de que os dispositivos que amparassem o afastamento do trabalho em razão do parto devessem ser acompanhados por um seguro-maternal, a ser financiado pela coletividade dos contribuintes. O objetivo, afirmavam, era preservar a empregabilidade das mulheres casadas. ${ }^{15}$

As feministas da FBPF, os deputados classistas da Constituinte, os líderes das bancadas dos católicos e dos tenentistas abraçaram a ideia de trazer para a esfera de competência da União a gestão das relações de trabalho de categorias profissionais consideradas importantes para a sustentação da atividade industrial. Para muitos, havia uma razão adicional para ampliar a proteção ao trabalho: evitar que os trabalhadores se convertessem em ameaça à ordem social, caso fossem contaminados pelo ativismo político. Assim, os parlamentares constituintes e os ativistas políticos disputavam entre si a capacidade de fazer valer os interesses de suas bases eleitorais e assegurar que os dispositivos de proteção ao trabalho - limitação de jornada, direito a férias, previdência social, entre outros - alcançassem as categorias que representavam na arena legislativa.

Desse modo, o texto final da Constituição foi um avanço na federalização da proteção ao trabalho das empregadas domésticas, mas era preciso assegurar que a legislação ordinária respeitasse o que a Constituição

15 LUTZ, Bertha. O Trabalho Feminino. A mulher e a ordem econômica e social. Rio de Janeiro: Imprensa Nacional, 1937; BITTENCOURT, Maria Luiza Dória. Trabalho Feminino. Rio de Janeiro: Borsoi, 1938. 
apenas definia como princípio. Assim, um conjunto de deputados classistas, liderados pelo único deputado negro da Constituinte, o deputado Antônio Rodrigues de Souza, propôs um projeto que criava o instituto de aposentadorias e pensões dos locadores do serviço doméstico, isto é, um instituto de previdência destinado a assistir às trabalhadoras do setor. ${ }^{16}$ O projeto $n .185$, apresentado em 20 março de 1935, constituía o esforço derradeiro do grupo para provocar a Câmara a discutir os direitos da categoria. Dos dez signatários do projeto de lei, apenas quatro foram reeleitos no pleito de 14 outubro de 1934 e retornariam à Câmara Federal em maio de 1935 para um novo mandato. ${ }^{17}$

Cerca de um mês antes de protocolar o projeto de lei, os deputados classistas teriam sido procurados pelo representante da União Doméstica, Joaquim Rufino dos Santos. A União Doméstica era uma entidade associativa sobre a qual pouco se sabe e que, segundo consta no projeto de lei, existia no Distrito Federal há mais de uma década, atuando em defesa dos interesses da categoria. A menção à iniciativa de uma entidade profissional de se aproximar de parlamentares para fazer chegar à categoria das domésticas os mesmos direitos que estavam sendo estendidos aos outros trabalhadores sugere que a categoria não permanecia passiva, a aguardar a boa vontade de parlamentares ou de autoridades do Estado.

Escolho palavras com cautela porque a pesquisa histórica ainda é insuficiente para afirmar de modo decisivo que a União Doméstica tenha surgido da iniciativa de trabalhadoras no setor. Sabe-se da existência de entidades civis que se apresentavam como defensoras das mulheres trabalhadoras, mas que, em verdade, defendiam os interesses das donas-de-casa, as empregadoras. Um exemplo notório foi a Legião da Mulher Brasileira, criada ao final do ano de 1920, na Capital Federal, e que contava com uma escola profissionalizante para empregadas domésticas. Anos depois, surgiu a Liga de Proteção ao Lar Pobre, que mantinha uma seção para apoiar empregadas domésticas e encaminhá-las a postos de

16 Projeto de Lei n. 185/1935. [Diário do Poder Legislativo (DPL), 22 mar. 1935, p.1.967]

17 Antônio Rodrigues de Souza fora eleito em 1933 pela categoria dos estivadores do Rio de Janeiro deputado classista à Assembleia Constituinte. 
trabalho. A Liga disputava, junto a outras tantas associações existentes na cidade, o título de entidade filantrópica, capaz de render significativas quantias em termos de subvenções do Estado. ${ }^{18}$

Imagem 1: Ficha funcional de Gilda Araújo Pareto à Liga de Proteção ao Lar Pobre - Rio de Janeiro.

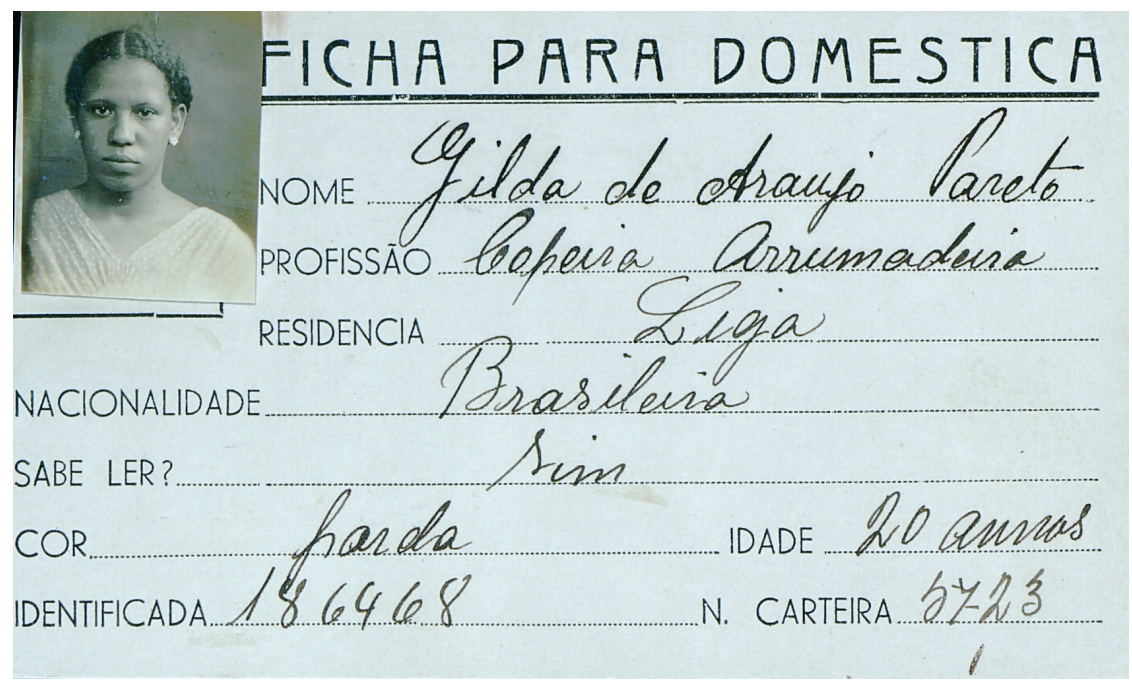

Fonte: Tramitação dos projetos 238 e 297/1935. Arquivo da Câmara dos Deputados [Localização: BR DFCD 1935/15/1]

O projeto de lei dos deputados classistas previa a criação de um instituto de aposentadorias e pensões a ser abrigado na estrutura administrativa do Ministério do Trabalho, Indústria e Comércio. ${ }^{19} \mathrm{O}$ projeto estipulava empregados, empregadores e o Estado contribuiriam para o fundo de previdência, na base de $5 \%$ do valor do salário, cada um.

18 A documentação relativa à tramitação do projeto 297/1935 contém os respectivos estatutos da Legião e da Liga, esta última, criada em 1936. [Arquivo Câmara: 1935; 926; 15;01;01] BRASIL. Câmara dos Deputados. Regimento Interno da Assembleia Nacional Constituinte. Rio de Janeiro: Imprensa Nacional, 1934.

19 DPL, 22 mar. 1935, p.1.967ss. 
A fim de evitar que surgisse conluio entre empregadores e empregados para sub-informar o valor do salário praticado, o projeto de lei estipulava o valor mínimo de $100 \$ 000$ para o salário mensal da categoria. Um valor reconhecidamente baixo para o custo de vida nas cidades, mas que, assim mesmo, foi objeto de muita crítica na imprensa, sob a alegação de que famílias de classe média baixa não poderiam mais arcar com o custo de contratar empregadas domésticas. ${ }^{20}$

O mais interessante aspecto do projeto de Rodrigues de Souza era que o texto reconhecia a existência legal e o papel ativo de sindicatos, caso estes viessem a surgir. Chama a atenção a proposta reconhecer como válida a mediação de associações beneficentes e, até mesmo de associações recreativas, que abrigassem empregadas domésticas. Os funcionários de tais entidades também contribuíram para o instituto de previdência a ser constituído. Ora, a recente produção historiográfica vem revelando a importância política de clubes recreativos e de associações culturais para as comunidades negras nas maiores cidades do país (Flores, 2007). O projeto de lei dos deputados classistas reconhece o valor político de tais entidades. Apesar disso e, talvez, por todos esses motivos, o projeto 185/1935 não caminhou na Câmara.

Como se vê, o projeto dos classistas afrontava o dispositivo imposto pelo Governo Provisório, que excluiu funcionários públicos e empregados domésticos do rol das categorias aptas a se organizarem na forma de sindicatos reconhecidos pelo Ministério do Trabalho, como já se comentou. Havia, portanto, muito em jogo na insistência em manter a vasta categoria dos prestadores de serviço doméstico à margem da legislação universal relativa ao trabalho.

Por essas razões, em complemento à proposta protocolada em março, o deputado Antônio Rodrigues apresentou mais um projeto, que regula “a locução dos empregados em serviços domésticos". Trata-se do projeto de lei n. 238, de 17 de abril de 1935. ${ }^{21}$ Nessa iniciativa, Rodrigues foi

20 PRADO, Rachel. O problema das domésticas, Correio da Manhã, 7 abr. 1935, suplemento dominical - Correio feminino, p.4.

21 DPL, 10/10/1935, p.1.935-1.969. 
acompanhado por outros sete deputados classistas, cujos nomes coincidem com parte do grupo que havia assinado o projeto de março. Dos oito parlamentares, apenas dois voltariam à Câmara no mês seguinte para tomar posse de suas cadeiras.

O projeto tratava da sensível questão das carteiras profissionais, tema sobre o qual as divergências de interesses entre os empregadores, os empregados e o Estado afloravam. No Distrito Federal, a categoria das empregadas, ao contrário dos demais trabalhadores, convivia com a identificação forçada desde 1923. A ideia dos classistas era reformar os dispositivos previstos no decreto de 1923, tornando-os extensíveis a todo o país e adaptá-los ao novo desenho administrativo do Estado. Assim, caberia ao Ministério do Trabalho emitir as carteiras, quando, antes, cabia apenas à polícia local fazê-lo. $\mathrm{Na}$ justificativa ao projeto, os proponentes informam que entidades representativas da categoria estiveram empenhadas, desde os anos 1920, em obter do Estado a identificação das trabalhadoras, no desejo de evitar o constrangimento de elas terem de pedir referências aos antigos patrões.

O regulamento de 1923, entretanto, atribuía à polícia o poder de reunir informações sobre toda a massa de trabalhadores do serviço doméstico na Capital Federal. O volume de trabalho envolvido era tamanho que, poucos anos depois, a chefatura de polícia do Distrito Federal suspendeu o serviço de controle das carteiras de domésticas. A medida marcou, no âmbito da Capital Federal, a saída do Estado da mediação das relações entre empregadores e empregados na Primeira República.

O mesmo regulamento estabelecia normas para a demissão de empregados que conferiam poder aos empregadores para julgar a conduta privada dos subordinados. Entre as causas que justificavam a demissão imediata, e sem compensação, estavam: "Vícios ou mau procedimento do locador".22 Claro está que esse dispositivo amparava os patrões para

22 BRASIL. Ministério do Trabalho, Indústria e Comércio. Legislação trabalhista. Consolidação das Leis do Trabalho. 3a edição. Rio de Janeiro: A. Coelho Branco, 1949. Decreto n. 16.107, 30 jun. 1923, art. 14, b. [DPL, 10 out. 1935, p.5.740.] 
julgar e condenar a conduta sexual de suas empregadas. A gravidez era uma sentença de desemprego para essas mulheres pobres.

De modo notório, o projeto do deputado Rodrigues Souza não recupera os dispositivos do regulamento de 1923 que definem motivos para a demissão justificada, porém, o tema retornou ao debate durante a tramitação da matéria porque o substitutivo ao projeto de Rodrigues, relatado pelo também classista, deputado Alberto Surek, manteve o dispositivo que condena a conduta do empregado como justificativa para demissão. Em termos administrativos, Surek concentra no Ministério do Trabalho a capacidade administrativa de emitir carteiras de trabalho das domésticas, além de acolher queixas de trabalhadores se os patrões não cumprissem a lei. O substitutivo, apresentado em julho de 1935, avançou ao regular o aviso prévio da demissão e conceder 15 dias de férias anuais à categoria, em substituição à previdência, que então se concedia a outras categorias no país. A partir desse ponto, o projeto passa a tramitar sob o número de 297/1935.

O substitutivo Surek enfatizava a nova atribuição do Ministério do Trabalho de prover um sistema de informação que controlasse a ampla categoria, tanto no quesito antecedentes criminais, quanto no quesito histórico de doenças contagiosas, ambas questões que afligiam os patrões, como se percebe nas manifestações na imprensa e nas peças elaboradas por parlamentares.

Já com o texto conferido pelo deputado Surek, o projeto é encaminhado à Comissão de Justiça em julho, onde para. ${ }^{23}$ Os debates não chegaram a um consenso sobre questões relativas aos trabalhadores domésticos, que, sabemos, se arrastaram por décadas à frente: concessão de férias, direitos previdenciários, trabalho infantil.

23 DPL, 10 out. 1935 , p.5.736. 


\section{ATORES SOCIAIS E TRABALHO DOMÉSTICO}

A matéria submergiu entre outras prioridades do momento no Legislativo, talvez porque já se cogitasse oferecer outra solução para regular o mercado do serviço doméstico no país. Enquanto os poderes públicos discutiam quem teria a incumbência de reunir informações sobre a vasta (e crescente) categoria das empregadas domésticas, entidades privadas se organizavam para prestar serviços às trabalhadoras e, assim, saber mais sobre as candidatas a emprego. Informações essas consideradas cruciais pelos empregadores: procedência, antecedentes, conduta, condição marital e estado de saúde.

Ao mesmo tempo em que, nos salões do Ministério do Trabalho, antigos deputados se sentavam com representantes patronais para discutir os destinos das empregadas domésticas, surgia a Casa da Empregada, erguida no bairro de Copacabana, pelo empenho dos paroquianos da Matriz São Paulo Apóstolo. A partir do ano de 1935, "senhoras da elite social carioca" promoveram chás e reuniões musicais para sustentar a obra social da Casa da Empregada. O primeiro grande evento social aconteceu ainda em julho de 1935, quando o teatro João Caetano recebeu "figuras de relevo social" para um recital em benefício da criação da Casa da Empregada. ${ }^{24}$ A primeira-dama, Darcy Vargas, integrantes da família Guinle e esposas de ministros de Estado prestigiaram o evento. Ano após ano, as senhoras promoveram algum evento em benefício da Casa da Empregada. Em novembro de 1938, novamente coube à primeira-dama prestigiar o chá da primavera, realizado nos salões do Automóvel Club. ${ }^{25}$

Além de cursos de aperfeiçoamento, a Casa oferecia alojamento provisório às trabalhadoras recém-chegadas à cidade, além de ambulatório médico e odontológico. As beneficiárias recebiam ali cuidados do corpo e do espírito, pois a Casa tinha por propósito incutir os ensinamentos morais necessários para o exercício da profissão nos lares da classe média

24 A Noite, 30 jul. 1935, p.1.

25 A Noite, 5 nov. 1938, p.4. 
— como sustentou a diretora da entidade ao repórter de A Noite. ${ }^{26}$ Os administradores do lugar reuniam as informações requisitadas pelas donas de casa, tarefa que o Ministério do Trabalho relutava em assumir sozinho. Para melhor desenvolver o projeto assistencial, obtiveram autorização do Ministério para distribuir carteiras de trabalho para as trabalhadoras e encaminhá-las para postos de trabalho. ${ }^{27}$ É importante ressaltar que a Casa da Empregada não oferecia creche para as associadas. Aliás, nenhuma entidade de assistência a empregadas existente no Rio o fazia.

O projeto da Casa cresceu com o apoio do governo federal, uma vez que o Conselho Nacional de Serviço Social, órgão integrado no Ministério da Educação e Saúde, autorizou subvenções anuais para a Casa da Empregada, assim como a numerosas entidades beneficentes no país. Basta consultar as peças orçamentárias para constatar que, ano após ano, a Casa contou com o apoio financeiro do governo. ${ }^{28}$

As antigas formas de assistência caritativa às empregadas domésticas pareciam acanhadas perto do escopo de atuação da Casa, em Copacabana. Em outros bairros, especialmente nos subúrbios, como também em outras cidades do país, existiam obras sociais devotadas a Santa Zita, uma santa católica, nascida na Itália, em 1218.

Nas associações de Santa Zita, as empregadas podiam frequentar a escola de alfabetização noturna e, em todos os anos, ao final de abril, celebrava-se o dia da santa com missa e quermesse. Motivo habitual na hagiografia católica, o sofrimento que, em vida, a menina Zita passou nas mãos de patrões violentos foram recompensados com a salvação de sua alma, amparada pela Virgem Maria. ${ }^{29}$

Em uma única ocasião naqueles anos, ao que se pode apurar, associadas de Santa Zita abandonaram a atitude resignada e tomaram as ruas

26 A Noite, 21 abri. 1936 (classificados); 8 ago. 1937, p.4.

27 A Noite, 25 jul. 1939, p.1.

28 BRASIL. Ministério do Trabalho, Indústria e Comércio. Legislação trabalhista. Consolidação das Leis do Trabalho. $3^{a}$ edição. Rio de Janeiro: A. Coelho Branco, 1949.Por exemplo: Decreto n. 242, 18 jul. 1935; Decreto n. 2.175, 13 dez. 1937; Decreto n. 4.309, 27 jul. 1939.

29 Gazeta de Notícias, 27 abr. 1904, p.3; Jornal do Brasil, 27 abr. 1928, p.9; 28 jun. 1938, p.10; 27abr. 1938, p.10. 
de Belo Horizonte para protestar contra um projeto de lei que então se discutia na Câmara Municipal da cidade. O projeto previa o fichamento das domésticas na polícia da capital mineira e, contra a medida, cerca de 300 empregadas caminharam em passeata pela cidade. Talvez alarmados com o ineditismo do caso, os jornais da Capital Federal deram destaque ao episódio. ${ }^{30}$

Imagem 2: Anúncio de agência de emprego

\section{Empregados Domesticos}

* (CÓsINHEIRAs, COPEIRAS, ARRUMADEIRAS, LAVADEIRAS, JARDINEIROS, ENCERADÔRES, ETC.) PARA TIRAR

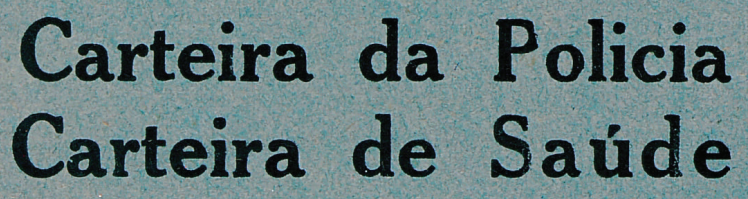
DIRIGIR-SE Á

Rua Copacabana, 895

DAS 14 ÁS 16 HORAS

Fonte: Tramitação dos projetos 238 e 297/35. Arquivo da Câmara dos Deputados [Localização: BR DFCD 1935/15/1]

Como se vê, a elite fez diversos experimentos para controlar a categoria das empregadas domésticas e assegurar que a convivência com essas mulheres pobres dentro dos lares não viesse a comprometer a integridade das famílias. A diferença notória entre as iniciativas da Legião da Mulher Brasileira, criada em 1921 e presidida pela Condessa de

30 A Noite, 26 fev. 1937, p.5. 
Afonso Celso, e a Casa da Empregada, criada em 1935, em Copacabana e mantida por paroquianos, era a inserção da segunda em um projeto de assistencialismo apoiado pelo Estado, ungido pela Igreja católica e organizado com ampla estrutura para suprir os empregadores com trabalhadoras sadias e dóceis.

Nesses anos, a questão do tratamento a ser dado à vasta categoria das empregadas nos lares foi objeto de variadas manifestações. Por ocasião da Semana de Ação Social, em setembro de 1936, a assistente social Heloisa Werneck apresentou uma tese, que foi posteriormente publicada em periódico do Ministério do Trabalho. ${ }^{31}$ Não sem antes invocar a encíclica Rerum Novarum, que fundamenta a obra de assistência social em construção no país, Werneck sustenta que as empregadas domésticas, assim como as operárias, deviam ser amparadas pela assistência social para que conhecessem seus direitos e obrigações.

Sem invocar a Rerum Novarum, mas baseando-se no ideário da justiça social, Bertha Lutz usa de suas prerrogativas como parlamentar para apresentar, em julho de 1937, um amplo projeto que reformula o estatuto jurídico da mulher no país. ${ }^{32}$ Do projeto, que Bertha redigiu em colaboração com a advogada Maria Luiza Bittencourt, constam artigos que estendem a todas as mulheres que exercessem atividade remunerada o direito a férias anuais, à previdência, e a limitação de horas de trabalho. O projeto também tornava ilegal o emprego de menores de 14 anos como empregadas domésticas ou aprendizes em oficinas, além de tipificar o crime de abuso físico contra a empregada doméstica, com agravante, caso se tratasse de menor sob a tutela do empregador. ${ }^{33} \mathrm{Tal}$ preocupação se justificava pela prática disseminada de admitir crianças no serviço doméstico, a ponto de o Censo de 1940 registrar 132.967 mulheres em atividade no setor, no Distrito Federal, com idades entre

31 WERNECK, Heloisa. O trabalho das mulheres e dos menores. Boletim do Ministério do Trabalho, Indústria e Comércio, nov./dez. 1936, n. 27, p.134-150.

32 Projeto n. 736/1937, de autoria da deputada Bertha Lutz.

33 Projeto n. 736/1937: artigos n. 31, 33, 91, 123. 
10 e 19 anos. $^{34}$ Esse contingente de meninas e adolescentes que atuavam nas casas da Capital Federal representa um quarto do total de mulheres que viviam do ofício na época.

No Ministério, as comissões que discutem o valor do salário mínimo e a regulamentação do trabalho doméstico debatem a inclusão, se parcial ou total, da categoria nas leis sociais. $\mathrm{O}$ assunto expõe a divergência interna entre os grupos que sustentam o governo Vargas, pois, ora há dispositivos que favorecem a categoria, ora surgem outros que a prejudicam.

Ainda em 1936, em complemento à Constituição, o governo baixou um decreto que regulava a definição regional do valor do salário mínimo. Essa medida estendia o salário mínimo aos servidores domésticos. ${ }^{35}$ Três anos depois, a questão continuava a gerar controvérsia no Ministério, onde uma comissão discutia o salário mínimo a ser praticado no Distrito Federal. O relator da matéria, o jornalista Ozéas Motta, sustentou que não cabia estipular um salário mínimo para as empregadas domésticas, sob pena de afetar o orçamento das famílias. ${ }^{36}$ Debatia-se, no entanto, qual o valor máximo que os patrões poderiam descontar do ordenado das empregadas, a título de alimentação e moradia. A Comissão do Salário Mínimo do Distrito Federal fixou esse valor em 123\$300. Como, segundo Motta, a maioria dos trabalhadores do setor, na capital federal, ganhava menos de $240 \$ 000$ por mês, a fixação do valor de 123 mil réis afetava empregadas que não residiam na mesma casa dos patrões, nem se alimentavam ali. Para tais pessoas, aplicava-se o que se dizia então: o salário a seco. Na prática, o Estado impedia os patrões de remunerar os empregados por menos de 123 mil réis, se estes coabitassem com a família dos patrões. Para um significativo número de mulheres, o salário real seria um pouco mais do

34 Recenseamento Geral do Brasil, 1940, Série Nacional, vol. II, tabela 62.

35 BRASIL. Ministério do Trabalho, Indústria e Comércio. Legislação trabalhista. Consolidação das Leis do Trabalho. $3^{a}$ edição. Rio de Janeiro: A. Coelho Branco, 1949. Decreto n. 185, 14 jan. 1936, art. $3^{\circ}, \S$ único.

36 A Noite, 16 mai. 1939, p.2. 
que 123 mil réis, um valor próximo ao custo estimado de alimentação e moradia de uma família de sete pessoas. ${ }^{37} \mathrm{Em}$ outros termos, praticava-se um salário de subsistência.

Novamente nos salões do Ministério, o mesmo Ozéas Motta relata o estudo que se fazia sobre os projetos de legislação social vindos da antiga Câmara dos Deputados. Justamente, o projeto n. 297/35 entrou em discussão na Comissão de Legislação Social, no dia 3 de outubro de 1939. Escreveu Motta: "Não é de aconselhar o completo abandono dos que se dedicam ao serviço pessoal de indivíduos. O fundamento deste amparo, porém, é de ordem mais humanitário do que social ou econômico". ${ }^{8}$ A despeito de pensar assim, sustenta que não cabia estender o amparo da previdência à categoria, nem regular a forma como o trabalho se desenvolveria nos domicílios, pois as condições variavam de casa a casa. Nada disse o relator sobre o emprego de menores nesses ambientes.

Dos debates havidos no Ministério do Trabalho, resultou a normativa de 1941, que tratava dos principais aspectos discutidos pelos empregadores nos anos anteriores: a atuação do Estado na identificação e no fornecimento de informações sobre antecedentes criminais dos trabalhadores. O serviço de inspeção de saúde, a cargo da administração pública, poderia ser provido por entidades privadas parceiras, desde que isso não implicasse em ônus para o poder público. Surpreendentemente, o decreto de 1941 previa que o Ministério do Trabalho se ocuparia em estudar uma fórmula para enquadrar os trabalhadores domésticos no sistema de previdência que se organizava, então. ${ }^{39}$

37 BRASIL. IBGE. Anuário Estatístico do Brasil. Ano V - 1939/1940. Rio de Janeiro: Serviço Gráfico do Instituto Brasileiro de Geografia e Estatística. Disponível em: https://biblioteca. ibge.gov.br/biblioteca-catalogo?id=720\&view=detalhes Acesso: abr. 2019. Anuário Estatístico do Brasil, 1939/1940, p.534.

38 Relatório de Ozéas Motta ao projeto 297/1935, em 3 out. 1939. [Arquivo Câmara: 1935; 926; 15; 01;01] Assinam o documento: Salgado Filho (presidente da Comissão), Ozéas Motta, Vicente Galliez, Deodato Maia, Alberto Surek.

39 BRASIL. Ministério do Trabalho, Indústria e Comércio. Legislação trabalhista. Consolidação das Leis do Trabalho. 3a edição. Rio de Janeiro: A. Coelho Branco, 1949. Decreto-lei n. 3.078, 27 fev. 1941. 
Patrões deveriam tratar seus empregados com "urbanidade", uma terminologia herdada da Legislatura de 1935-1937; empregados tinham o dever de prestar obediência e respeito ao empregador, além de responder, em dinheiro, por danos que causassem ao patrimônio da família.

Excluída da Consolidação das Leis do Trabalho, editada em maio de 1943, a categoria dos empregados domésticos era regida pelo decreto de 1941. Entretanto, como o decreto de 1941 jamais foi regulamentado, fosse porque indicava a intenção de o Estado regular a espinhosa matéria dos direitos previdenciários da categoria, fosse porque impedia entidades privadas de receberem subvenção do Estado por prestarem serviços auxiliares, a categoria, na prática, continuou fora do alcance da fiscalização do Estado e sujeita ao se que se passava no segredo das casas.

As feministas da FBPF, que tanto se bateram naquelas décadas pelo reconhecimento do valor social do trabalho exercido por mulheres, recuaram da posição crítica que haviam assumido quando no exercício do mandato parlamentar. No lugar da crítica à prática do trabalho infantil no setor, dos abusos físicos e morais dos patrões feitos longe da vista do público, e da exclusão da maior categoria funcional feminina de direitos previdenciários, a feminista Maria Luiza Bittencourt escreveu em 1938 que os costumes bastariam para regular a vida das empregadas nos lares: ${ }^{40}$

O trabalho doméstico propriamente dito, isto é, o que se executa dentro do lar, este escapa à regulamentação legal, tanto quanto o do ateliê, em que se empregam os membros de uma só família. Nestes ramos, porém, entre nós, como na maioria dos países, do Ceilão à Suécia, a brandura dos costumes e os hábitos de longa permanência em trabalho servil, estabeleceram uma familiaridade que ainda hoje persiste, entre

40 BITTENCOURT, Maria Luiza Dória. Trabalho Feminino. Rio de Janeiro: Borsoi, 1938, p.84. Consultados vários acervos, foi localizado um único exemplar da obra de Maria Luiza Bittencourt, a constar do acervo da biblioteca do STF, como parte da coleção do ministro Levi Carneiro. 
o empregado doméstico e a família a que serve, permitem que o nível de vida não seja rude e as praxes de repouso semanal e descanso sejam mais ou menos respeitados, compondo-se a remuneração pequena que em dinheiro percebe, de um acréscimo, feito de prestações em espécie (residência, vestiário de trabalho, alimentação) de maneira a permitir que suas condições de vida não sejam miseráveis.

Argumentos semelhantes sustentam o relatório da comissão que elaborou a CLT, quando esta buscou justificar a exclusão do serviço doméstico das leis de proteção ao trabalho: "A vida familiar apresenta aspectos de nenhuma similaridade com as atividades econômicas em geral, nem mesmo com as de beneficência. Estender-lhe o plano de uma legislação feita e adequada a outras condições pessoais e ambientes seria forçar a realidade das coisas". ${ }^{41}$

A CLT, como se sabe, resultou do trabalho de uma comissão de juristas, constituída no Ministério do Trabalho, que tinha por propósito reunir a legislação social editada desde 1931. Segadas Vianna foi um dos juristas responsáveis pela Consolidação e com ele Bertha Lutz e Maria Luiza Bittencourt mantinham interlocução política. Vianna, que se opunha aos grupos internos no Ministério que defendiam o controle da Igreja sobre os sindicatos, respondeu pelo capítulo relativo ao trabalho da mulher na CLT. Ao justificar as escolhas feitas pelos integrantes do governo, Segadas Vianna consagra as palavras de Bittencourt, ao citar integralmente o trecho transcrito acima. ${ }^{42}$ Nas gerações de advogados que conheceram o Direito de Trabalho a partir da obra de Vianna, fixou-se a convicção de que era justo as trabalhadoras domésticas viverem à margem da proteção da legislação social, sendo suficiente contar com a boa fé dos empregadores.

41 MARCONDES, Alexandre. Exposição de motivos do Sr. Ministro do Trabalho, Indústria e Comércio. Diário Oficial da União, Suplemento ao n. 3. Diário Oficial da União, 5 jan. 1943, p.3.

42 VIANNA, Segadas. Trabalho da Mulher. In SUSSEKIND, Arnaldo; MARANHÃO, Délio; VIANNA, Segadas. Instituições de Direito do Trabalho. São Paulo: Livraria Freitas Bastos, 1961. [2a Edição]. p.243. 
Com a proximidade do final da guerra e a necessidade de discutir no plano diplomático questões urgentes sobre as relações de trabalho, a questão dos direitos das mulheres à proteção da legislação social retornou ao debate internacional. Bertha Lutz foi nomeada por Vargas para integrar a delegação brasileira à Conferência Internacional do Trabalho, que aconteceu na Filadélfia, EUA, em maio de 1944. Durante os dias da conferência, Lutz defendeu medidas em favor da igualdade salarial entre homens e mulheres, medidas para evitar o emprego de menores na indústria, além do compromisso de se evitar que mulheres vivessem em condições análogas à servidão. ${ }^{43} \mathrm{~A}$ atuação de Lutz nos dias da conferência repercutiu na grande imprensa norte-americana. ${ }^{44}$

Mas, dentre as iniciativas de Lutz na conferência de 1944, foi a proposta de auxílio-maternidade que mereceu maior destaque por Segadas Vianna, então responsável no Ministério por acompanhar os debates nos organismos internacionais de trabalho e de previdência. A proposta de Lutz foi consagrada e se converteu em recomendação aprovada no plenário da Conferência. ${ }^{45} \mathrm{~A}$ iniciativa, que era amparada pelo Itamaraty e sustentada politicamente pelo Ministério do Trabalho, colocava o Brasil na vanguarda da defesa da maternidade social entre os integrantes da Organização Internacional do Trabalho.

Para Lutz, fechava-se o ciclo iniciado em 1933, quando a então candidata à Câmara Federal defendera a instituição de uma forma de amparo estatal à maternidade, de modo a retirar do empregador o ônus de arcar com o afastamento da trabalhadora em função do parto e, assim, preservar a empregabilidade da mulher na indústria. A defesa das empregadas domésticas, porém, foi abandonada em 1944 em nome de uma pauta mínima de negociação com os poderes constituídos: a maternidade social das operárias.

43 International Labour Office. Resolutions Adopted by the 26th Session of the International Labour Conference (Philadelphia, April-May, 1944). Montreal: ILO, 1944.

44 BARCLAY, D. ILO Group Weighs Equal-Pay Issue. The New York Times, 3 mai. 1944, p.15. 45 VIANNA, Segadas. Trabalho da Mulher, 1961, p.252; ILO, Resolutions, 1944, p.5. 
Tanto Bertha Lutz, como Maria Luiza Bittencourt (que estivera em Harvard), acompanhavam os desdobramentos políticos da questão da regulação do trabalho exercido por mulheres nos Estados Unidos. Sabiam, por intermédio de publicações e por manterem correspondência com interlocutores norte-americanos, que o debate se dava em torno da competência do governo da União para ditar normas aplicáveis nos estados da federação, em matéria de legislação sobre o trabalho. De fato, o governo Roosevelt definiu novas regras para o emprego de muitas categorias funcionais, no entanto, a numerosa categoria das trabalhadoras nos lares foi mantida na informalidade e à mercê de patrões até os anos 1970, o alcance das medidas do governo da União não chegou até os estados da federação, por sofrerem forte oposição (Mettler, 1994).

Comparativamente aos Estados Unidos, no Brasil, o movimento de 1930 trouxe a questão social para a esfera de competência do governo federal, uma tendência que o Estado Novo consagrou. Nesses anos, as feministas da FBPF se posicionaram na arena política a fim de, a partir da centralização política nas mãos do chefe do Executivo, melhor negociar os termos da proteção do trabalho da mulher e a igualdade salarial com os homens.

Para as feministas da FBPF, o Estado Novo significou o fechamento do acesso a carreiras públicas para mulheres de classe média e crescentes dificuldades para mulheres obterem empregos formais. Sabia-se, porém, que as mulheres negras continuavam a estar sobre-representadas no serviço doméstico, um setor que, como se viu, não foi amparado pelo mesmo grau de proteção estendido às demais categorias de trabalhadoras.

No decurso do debate sobre o que fazer com as mulheres que trabalhavam nos lares, as feministas da FBPF não tiveram força, ou não desejaram, opor-se a grupos poderosos e bem articulados que haviam encampado a questão do trabalho doméstico após o encerramento da Constituinte. O seu posicionamento político, além de omisso, revela a contradição do discurso em defesa da Mulher universal, conceito usual na retórica feminista da Federação. Seriam as mulheres pobres que viviam do serviço doméstico uma outra humanidade, ou, se o leitor me 
permite o neologismo, uma outra "mulheridade", cujo direito à maternidade amparada e à previdência não deveria ser reconhecido pelo Estado? A resposta que apresentaram aos desafios do seu tempo sugere a persistência da ideia da subordinação das mulheres pobres, sobre as quais se ergueria a emancipação econômica e política das mulheres de classe média.

Do ponto de vista da opinião dominante nos setores integrados ao círculo do poder varguista, o serviço doméstico não se enquadrava na concepção teórica de trabalho, que compreendia apenas as atividades capazes de agregar valor ao capital. Os termos encontrados nos documentos do Ministério e nos jornais publicados sob a censura do Estado Novo insistiam que os "empregados domésticos não cooperam com o capital", logo, não cabe ao Estado estender a legislação social a essa categoria. ${ }^{46}$

Diferente era a concepção teórica de trabalho que Maria Luiza Bittencourt sustenta na sua obra. Para a advogada e feminista, trabalho é todo serviço que se presta a alguém mediante a expectativa de remuneração, em dinheiro. Trabalhador e empregador colaboram um com o outro, mas divergem entre si quanto a interesses. ${ }^{47}$ No entanto, a sua reflexão sobre os fundamentos teóricos do direito do trabalho não conduz a autora a reconhecer o emprego doméstico como uma forma de trabalho que também deveria ser protegida pela legislação.

Um e outro grupo mantinham-se sob a névoa da negação do racismo difuso que havia no Brasil. O elogio às relações amenas entre as raças impede a elite de reconhecer seus atos como capazes de perpetuar as desigualdades raciais no país. Racismo é o que se pratica na Alemanha nazista e nos Estados Unidos, antíteses da convivência harmoniosa entre as raças que existe no Brasil. O próprio Vargas oferece o formato do discurso sobre as relações sociais no país, quando se dirige à nação no 7 de setembro de 1942, no grave momento que se vive após o anúncio

46 A Noite, 16 mai. 1939, p.1; Arquivo Câmara: 1935, 926, 15, 01,01.

47 BITTENCOURT, Maria Luiza Dória. Trabalho Feminino. 1938, p.95. 
da declaração de guerra ao Eixo. No discurso pronunciado por Vargas e reproduzido nos jornais de todo o país, a certa altura se lê:: ${ }^{48}$

As consequências da luta em que nos empenhamos e que decidirá os destinos do mundo não podem causar-nos apreensões. Os privilégios de casta, os preconceitos raciais, as desigualdades de fortuna, as opressões de classe, os ódios mesquinhos, todos os valores aparentemente inconciliáveis da civilização contemporânea, hão de fundir-se nesse incêndio de vastas proporções em holocausto ao surto de uma nova era. O Brasil, como país jovem, de estrutura social plástica, rico de possibilidades e com uma formação de equilíbrio adaptável a todas as transformações, está naturalmente projetado para o futuro e nele terá de encontrar a solução definitiva das equações de seu progresso.

Em conjuntura diversa e já acossado por opositores que falam abertamente que Vargas deve deixar o poder, o Presidente se manifesta: "Não preciso ir buscar exemplos nem lições no estrangeiro. Possuímos os princípios da democracia em nossas tradições de democracia política, étnica e social." ${ }^{49}$

No mesmo diapasão, Oliveira Vianna exalta a importância da obra social varguista, que estende à classe trabalhadora o alcance da proteção da lei. Particularmente, a mulher, que, por contingência da vida, é obrigada a buscar o sustento da família fora do lar, também é protegida pelo Estado. A verborragia de Vianna contrasta com o silêncio em torno da falta de amparo dos poderes públicos à maior categoria de trabalhadoras em atividade no país - as empregadas domésticas:

Bem o revelam várias leis ultimamente promulgadas relativas à higiene do trabalho e à alimentação racional do trabalhador. Bem o revelam, igualmente, as leis relativas à preservação da saúde da raça, seja pela

48 VARGAS, Getúlio. “Discurso na Hora da Independência”, Correio da Manhã, 8 set. 1942, p.1.

49 Discurso de Vargas pronunciado em 3 out. 1945. Consta dos papéis de Getúlio Vargas, conservados no CPDOC. [GV c1945.10.01/3] 
regulamentação do trabalho da mulher, seja pela regulamentação do trabalho do menor. Bem o revela a nova orientação dos serviços médicos das nossas instituições de previdência. (Vianna, 1942, p.395) ${ }^{50}$

No plano das relações quotidianas, as representações sobre as empregadas domésticas mal disfarçam a persistente mentalidade senhorial. Por exemplo, ao descrever, as atividades desenvolvidas pela Casa da Empregada, a gestora do projeto, que o jornal identificou como Dona Chiquita, exaltou a colaboração de domésticas veteranas: "elementos que pertencem há longos anos à mesma patroa. Foram elas as pioneiras da iniciativa". 51

Sorte da patroa que tem a seu serviço a fiel empregada de muitos anos. A maior parte se vê às voltas com meninas, que tentam controlar. Na impossibilidade de fazê-lo sozinhas, pedem auxílio dos poderes públicos, para que, no uso dos meios políticos próprios de uma ditadura, coíbam o lazer que desvirtua as jovens empregadas. Abigail Lima, uma advogada que havia participado da criação da Legião da Mulher Brasileira, em 1921, apresenta sugestões à comissão que examina a regulação da categoria no Ministério do Trabalho, escrevendo-lhe desse modo: ${ }^{52}$

Para levar a efeito esta iniciativa, muito auxiliaria o regulamento da Comissão Social para que as delegacias de costumes e menores proibissem o funcionamento de Dancing semanais e diários, que muito concorrem para a corrupção da classe e desorganização do pessoal doméstico, que deixa de cumprir com seus deveres profissionais, faltarão às aulas, enquanto prejudicam física e moralmente as domésticas de menor idade. Dacings estes em grande número nesta Capital.

50 VIANNA, J. Oliveira. O problema social brasileiro e o papel das instituições sindicais e de previdência. In D.I.P. Os grandes problemas nacionais, Rio de Janeiro: Departamento de Imprensa e Propaganda, 1942.

51 A Noite, 8 ago. 1937, p.4.

52 Tramitação do projeto 297/35: "Sugestões de Abigail Lima à Comissão de Legislação Social”, 25 mai. 1939. [Arquivo Câmara: 1935, 926, 15, 01,01] 


\section{CONSIDERAÇões FINAIS}

$\mathrm{O}$ artigo buscou elucidar as razões que levaram o governo Vargas a não estender à ampla categoria dos empregados domésticos a legislação de proteção social. O tratamento oferecido à esta categoria, onde predominavam as mulheres pobres e persistia o trabalho infantil, entra em contradição com toda a retórica da legislação social sobre a presença de mulheres no mercado de trabalho, que se observa desde a instituição do Ministério do Trabalho, baseada no enaltecimento do papel social da mulher como mãe e na restrição à exploração do trabalho de crianças.

Os elaboradores da CLT argumentaram que o emprego doméstico não contribuía com o lucro do capital e, por isso, caberia regular a atividade separadamente. A decisão dos formuladores da CLT não deve ser tomada como um descuido, uma vez que a pesquisa revelou que, desde a Constituinte de 1933-1934 a questão do emprego doméstico havia mobilizado muitos setores sociais e requerido muita política energia, tanto dos defensores da categoria, como dos grupos que encamparam a questão para oferecer eles próprios uma solução ao problema. Particularmente, setores católicos se articularam para oferecer uma solução paralela ao Estado à questão do controle sobre os prestadores de serviço nos lares. A forma como a CLT trata, ou ignora, a categoria dos domésticos é, portanto, o resultado de um longo e duro embate entre as forças políticas que disputaram entre si ter a última voz sobre essa categoria.

Ao fim, as trabalhadoras domésticas não puderam contar com o apoio de nenhum grupo político influente no governo Vargas. Um breve ensaio foi feito ainda em 1935, quando parlamentares eleitos por bases sindicais se mobilizaram em torno de projetos de lei em benefício da categoria. Tais projetos, ou não tiveram andamento, ou foram distorcidos no percurso do processo parlamentar, que teve sua continuidade no âmbito do Ministério do Trabalho.

As relações entre a elite empregadora e a massa das mulheres envolvidas no trabalho doméstico, frequentemente por falta de opções, reproduziram formas de sujeição, fortemente vincadas por um persistente e mal disfarçado racismo das elites. 


\section{Agradecimentos}

A autora deseja agradecer o apoio que recebeu da equipe de arquivistas do Arquivo da Câmara dos Deputados e de Daniela Traldi.

\section{REFERÊNCIAS BIBLIOGRÁFICAS}

CARVALHO, José Murilo. Cidadania no Brasil: o longo caminho. Rio de Janeiro: Civilização Brasileira, 2003.

CPDOC. Dicionário Histórico Biográfico Brasileiro. Disponível em: https:// cpdoc.fgv.br/acervo/dhbb. Vários acessos entre mar. e mai. 2019.

CUNHA, Olívia Maria Gomes da. Criadas de servir: domesticidade, intimidade e retribuição. In GOMES, Flávio dos Santos; CUNHA, Olivia Maria Gomes da (org.). Quase cidadão: histórias e antropologias da pós-emancipação no Brasil. Rio de Janeiro: FGV, 2007.

FLORES, Élio Chaves. Jacobinismo negro: lutas políticas e práticas emancipatórias (1930-1964). In REIS, Daniel Aarão; FERREIRA, Jorge (org.). A formação das tradições (1889-1945). Rio de Janeiro: Civilização Brasileira, 2007, vol. I.

GOMES, Ângela Maria de Castro. A representação de classes na Constituinte de 1934. In GOMES, Ângela Maria de Castro.(coord.). Regionalismo e centralização política: partidos e Constituinte nos anos 30. Rio de Janeiro: Nova Fronteira, 1980.

MARSHALL, Thomas Humphrey. Citizenship and social class and other essays. Cambridge: Cambridge University Press, 1950.

METTLER, Suzanne. Federalism, Gender, \& the Fair Labor Standards Act of 1938. Polity, vol. 26, n. 4, p.635-654, 1994.

MARQUES, Teresa Cristina de Novaes; MELO, Hildete Pereira de. Os direitos civis das mulheres casadas no Brasil entre 1916 e 1962: ou como são feitas as leis. Revista Estudos Feministas, vol. 16, n. 2, p.463-488, 2008.

MARQUES, Teresa Cristina de Novaes. Perfil Parlamentar: Bertha Lutz. Ação feminista e sistema político brasileiro. Brasília: Edições Câmara, 2016a. 
MARQUES, Teresa Cristina de Novaes. A regulação do trabalho feminino em um sistema político masculino, Brasil: 1932-1943. Estudos Históricos, vol. 29, n. 59, p.667-686, 2016b.

MOURA, Roberto. Tia Ciata e a pequena África no Rio de Janeiro. Rio de Janeiro: Secretaria Municipal de Cultura, 1995.

PEREZ, Inés; CUTULI, Romina; GARAZI, Débora. Senderos que se bifurcan. Servicio doméstico y derechos laborales en la Argentina del siglo XX. Mar del Plata: Eudem, 2018.

RODRIGUEZ, Dinah; COOPER, Jennifer. (comp.). Debate sobre el trabajo doméstico. Antología. México: Instituto de Investigaciones Económicas, 2005.

SILVA, Maciel Henrique Carneiro. Domésticas criadas entre textos e práticas sociais: Recife e Salvador, 1870-1910. Tese de Doutorado em História, Universidade Federal da Bahia, 2011.

SOUZA, Flávia Fernandes de. Trabalho doméstico: considerações sobre um tema recente de estudos na História Social do Trabalho no Brasil. Revista Mundos do Trabalho, vol. 7, n. 13, jan-jun, p.275-296, 2015. 